Ambient Science, 2016: Vol. 03(Sp1); 64-68

DOI:10.21276/ambi.2016.03.sp1.ra10

ambient

SCIENCE

Vol. 3(Sp1):64-68

Year 2016

RESEARCH ARTICLE

\title{
Pregnancy Related Anxiety Questionnaire: Reliability, Validity and Factor Analysis
}

\section{Poneh Purkhajuee $^{1 *}$, Nasser Behroozy ${ }^{2}$, Mahssa Karamozian ${ }^{3}$ \\ ${ }^{1}$ Department of Psychology, Kerman University of Medical Sciences, Kerman, Iran \\ ${ }^{2}$ Department of Educational Psychology, Shahid Chamran University of Ahvaz, Ahvaz, Iran \\ ${ }^{2}$ Department of psychology, Shahid Bahonar University of Kerman, Iran}

Study Area: Kerman, Iran

Coordinate: $29.4850^{\circ} \mathrm{N}, 57.6439^{\circ} \mathrm{E}$

Keywords:

\begin{abstract}
Anxiety has an important role in various fields of psychology and certainly in specif ic periods of human life. This study is to focus on confirmatory factor analysis of Pregnancy-Related Anxiety Questionnaire (PRAQ) that has been designed by keeping in mind the Iranian pregnant women population. After confirming the validity and content to the psychometric tool, 170 pregnant women in health centres of Kerman city were selected through random sampling method to fill-up the PRAQ questionnaire and Beck Anxiety Inventory. Based on the results it could be concluded we Iranian have not much difference in components of pregnancy anxiety while comparing with the cases of the other countries. This study certainly would introduce a tool which could be beneficial in measuring anxiety and concerns of women during pregnancy.
\end{abstract}

alarmingly low (Bunevicius \& Cesnaite, 2007; Goodman \& Tyer-Viola, 2010). Anxiety during pregnancy and childbirth also effects to the baby suffering from schizophrenia (Isohanni et al., 1966), and emotional disorders in coming future (O'Keane, 200o), autism (Dennis et al., 2008), hyperactivity (Van den Bergh et al., 2005), and shortness of breath during neonatal period (Cookson et al., 2009). There is a direct relationship between the anxiety of mother and abnormal fetal brain development (O'Connor et al., 2002), fetal distress (Bhagwanani et al., 1997) and a reduction in mental development at the age of 2 (Solchany, 2003). The prenatal anxiety of mother is reported to get the effect on sleep disorders of children, and behavioural problems in early childhood (O'Connor et al., 2007). The importance of mental health in pregnancy is noteworthy that the root of poor attachment of parent-child during postpartum depression lies during pregnancy period (Farland et al., 2011). Many studies have shown the relationship between the high levels of cortisol (which is influenced by the mother's anxiety and stress) with risks of low birth trauma and psychological disorders (Rahman \& Creed, 2007).

Anxiety in pregnancy and childbirth have harmful effects; and in the long-term anxiety by stimulating the autonomic nervous system, smooth muscles of arteries constrict and Uterus-placenta blood flow and oxygen 
supply to the uterus drop; and as a result, fetal heart rate pattern become abnormal and risk of preterm delivery could be increased (Arai et al., 2009). Hence, premature birth and low birth weight lead to negative consequences in the physical and cognitive development of children and these babies would more likely to suffer from cerebral palsy, learning disabilities and other disabilities (Kammrer et al., 2002). Moreover, anxious and depressed mothers are not sensitive to the messages conveyed by theirchildren (Punamaki et al., 2006).

The prevalence of anxiety disorders may also have reverse effects on results of obstetric, fetal and neonatal (Bunevicius \& Cesnaite, 2007). It is also noteworthy to mention that mental health problems during pregnancy have been studied in 90\% of high-income countries; unfortunately, while compared only $10 \%$ of low and middle-income countries have available information (WHO, 2014).

Studies have shown that pregnant women may have grave concerns about the failure of the embryonic period, concerns about the pain and worry towards the changes in their personal lives as a result of pregnancy and childbirth (Dunkel-schetter, 1998). The shortcomings in measuring mental state of the mother during pregnancy can estimate their mental turmoil far less than the actual values (Dipietro et al., 2004). However, the early detection, prevention and management of anxiety during pregnancy make women able to meet the challenges of pregnancy (Madhavanprabhakaran et al., 2015). Therefore, knowing the fears and concerns specifically during the pregnancy and reviewing the changes of pregnancy-related anxiety and clinical factors associated with it seem essential.

\section{Materials and methods:}

We conducted a descriptive survey associated with a toolmaking study upon such pregnant women who had visited the medical health centres in Kerman during the second half of 2014 for medical cares. Total 170 women were selected and evaluated with cluster random sampling method over a period of one month. For this study, Kerman city was hypothetically divided into four regions i.e., North, South, East and West and one health centre randomly selected from each region. Criteria for inclusion were being Iranian, having enough knowledge to fill up the questionnaires of the study, having well physical and mental health as well as having a normal pregnancy and healthy fetus.

Sample size: standardizing the sample size in an exploratory analysis follows the principle of sampling i.e. number of participants is always greater than the number of questions in the questionnaire (Martin \& Vance, 1994) so a range of 5 to 20 participants for each question is considered (Nouri et al., 2010) Therefore, as per Stevens the number of questions which were 17 , three sample size of 170 people (per question 10) was determined and taking 10 percent chance of loss, questionnaire was given to 187 pregnant women and finally, 170 questionnaires were fully completed by pregnant women.

\section{Research Tools}

1- Demographic questionnaire: age, number of pregnancies and education were collected using demographic questionnaire.

2- Pregnancy Related Anxiety Questionnaire: it was the main research tool which evaluated fears and concerns about contraceptive, forwarded by Van den berg (1990). The pregnancy anxiety questionnaire includer7 items, thus referred as PRAQ-17. Exploratory factor analysis of the questionnaire revealed five factors: i) fear of childbirth ( 3 items), ii) fear of giving birth to a child with physical or mental health issues ( 4 items), iii) fear of change in the marital relationship ( 4 items), iv) fear of changes in mood and its consequences on the child ( 3 items), v) self-centered fear or fear of the changes in personal life of mother ( 3 items). The final score was obtained from the sum of all the scores gathered from the questionnaire. Each item was graded between one and seven. In such way, the pregnancy anxiety grade would be between 17 and 119 .

3- Beck Anxiety Inventory (BAI): this questionnaire consists of 21 items to covers the most common symptoms of anxiety. The phrase reflects one of the symptoms of anxiety that usually people who are clinically anxious or who are in a state of great anxiety do realise. The ratings were given as; i) Not at all (o), ii) mildly (1), iii) moderately (2) and iv) severely (3). If participant earned a score between o to 7 then no anxiety; between 8 to15 - mild anxiety; between 16 to 25 - moderate anxiety and if between 26 to 63 than severe anxiety (Beck \& Steer, 1990).

Earlier studies showed that the questionnaire has high reliability and validity. Its internal consistency coefficient is 0.92 , its reliability with the help of testretesting method within a week is 0.75 and the correlation of its items varies from 0.30 to 0.70 . Five types of content validity, concurrent, construct, diagnostic and a factor for this test measured which all of them indicative the effectiveness of this tool in measuring of anxiety in Iranian population (Kaviani \& Mousavi, 2008).

This study conducted with obtaining permission from the Ethics Committee of health centres in Kerman. All participants in the study were informed and assured them that the information gathered will be used only for the purpose of research. Participants are also noted that are able to withdraw from the research process any time they want. The correlation matrix was used to analyse the data. Cronbach's alpha was used to evaluate the reliability of questionnaires and split-half method was used to evaluate the reliability of the study, and to evaluate factor 
structure of it confirmatory factor analysis and model parameters in the AMOS software and SPSS-19 were used.

\section{Results:}

In this study, 187 pregnant women participated for the confirmatory factor analysis where 170 participants were properly filled out the questionnaire in full. Table 1 shows participants' details.

Table 1: Characteristics of Mothers (would be)

\begin{tabular}{lll}
\hline Mother's characteristics & Name of group & Frequency \\
\hline Age & $18-30$ & $72-\% 42$ \\
& $30-35$ & $58-\% 34$ \\
& $35-40$ & $32-\% 19$ \\
Level of education & $>40$ & $8-\% 5$ \\
& Under Diploma & $42-\% 25$ \\
& Diploma & $97-\% 57$ \\
& Bachelor of science & $16-\% 9$ \\
Number of pregnancy & Master of science & $10-\% 6$ \\
& PHD & $5-\% 3$ \\
& 1 & $59-\% 35$ \\
& 2 & $48-\% 28$ \\
& 3 & $36-\% 21$ \\
& $4 \&$ more & $27-\% 16$ \\
\hline
\end{tabular}

Table 2. Factor structure short PRAQ

\begin{tabular}{llllll}
\hline Factors & $\mathrm{FD}^{5}$ & $\mathrm{FI}^{4}$ & $\mathrm{FC}^{3}$ & $\mathrm{CPR}^{2}$ & $\mathrm{CFR}^{1}$ \\
\hline Q3 & 0.37 & & & & \\
Q 5 & 0.66 & & & & \\
Q15 & 0.55 & & & & \\
Q1 & & 0.59 & & & \\
Q6 & & 0.42 & & & \\
Q9 & & 0.62 & & & \\
Q13 & & 0.44 & & & \\
Q 4 & & & 0.39 & & \\
Q11 & & & 0.42 & & \\
Q16 & & & 0.49 & & \\
Q7 & & & & 0.39 & \\
Q10 & & & & 0.44 & \\
Q17 & & & & 0.4 & 0.47 \\
Q 2 & & & & & 0.66 \\
Q 8 & & & & & 0.59 \\
Q12 & & & & & 0.46 \\
Q14 & & & & & \\
\hline
\end{tabular}

'Concern for oneself and the partner relationship during pregnancy

${ }^{2}$ Concern about future mother-child, father-child relationship and partner relationship

${ }^{3}$ Fear for delivery

${ }^{4}$ Fear for the integrity of the baby

${ }^{5}$ Fear for changes

Evaluate the validity of pregnancy-related anxiety questionnaire: in this study, in order to evaluate the validity of pregnancy-related anxiety questionnaire factor analysis and concurrent validity were used. Analysis of factors: conf irmatory factor analysis was done in order to verify the assumed factor structure in measuring anxiety in pregnant women. The goal was to compare the basic structural matrix with the new structural matrix. Finally the content of each factor and also the basic structural matrix reaffirmed. Table 2 presents loading factor on each of the questions that show the correlation of each question with the desired area. As mentioned table and Figure 1 show, the factor loadings on subjected factors are significant. In factor analysis, the minimum load factor was considered as

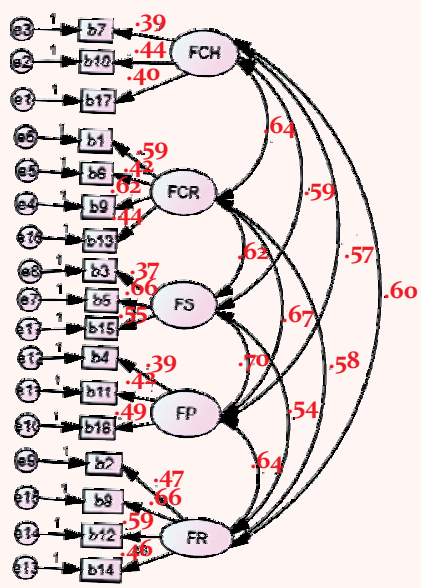

Figure- 1: The output model for the PRAO factors in AMOS. 0.30 .

The results of Confirmatory Factor Analysis fit indexes for the 5 -factor model in AMOS are as follows: RMSEA- 0.05; NFI-0.90; CFI-0.94; AGFI-0.92; TLI-o/90; IFI-o/94; GFI-o/95; $\chi_{2} / \mathrm{df}-3.75 ; \chi_{2}-51 ;$ Fitness index-80.56.

In the present study According to Schumacker \& Lomax (2010) is considered TLI significantly above criteria (TLI> 0/95); and CFI index value close to 1 as a significantvalue.

Concurrent validity: Beck Anxiety Inventory was used to evaluate concurrent validity that its correlation coeff icient with the subjected tools and its related factors has been mentioned above. As could be seen, based on the Pearson correlation coefficients, there is a positive correlation $(\mathrm{p}<0.01)$ between the total score of the PRAQ questionnaire and its factors and Beck Anxiety Inventory. Internal correlation of factors with each other and with the total score shows the reliability of factor structure. As much the correlation of factors with the total score is higher, and then the internal validity of the questionnaire is increased.

Table-3: Correlation coefficients and internal consistency between the scales and original questionnaire.

\begin{tabular}{lllllll}
\hline Factors & FC & FI & FD & CFR & CPR & General \\
\hline FC & 1 & & & & & \\
FI & $0.62^{* *}$ & 1 & & & & \\
FD & $0.70^{* *}$ & $0.66^{* *}$ & 1 & & & \\
CFR & $0.59^{* *}$ & $0.64^{* *}$ & $0.57^{* *}$ & 1 & & \\
CPR & $0.54^{* *}$ & $0.58^{*}$ & $0.67^{* *}$ & $0.60^{* *} 1$ & \\
General & $0.77^{* *}$ & $0.74^{* *}$ & $0.70^{* *}$ & $0.75^{* *}$ & $0.72^{* *}$ & 1 \\
BAI & $0.64^{* *}$ & $0.70^{* *}$ & $0.59^{* *}$ & $0.66^{* *}$ & $0.62^{* *}$ & $0.74^{* *}$ \\
\hline
\end{tabular}

${ }^{* *} \mathrm{p}<0.01$

FC-fear for changes; FI- fear for the integrity of the baby; FD-fear for delivery; CFR-concern about future mother-child, fatherchild relationship and partner relationship; CPR- concern for oneself and the partner relationship during pregnancy; GeneralGeneral anxietyscale. 


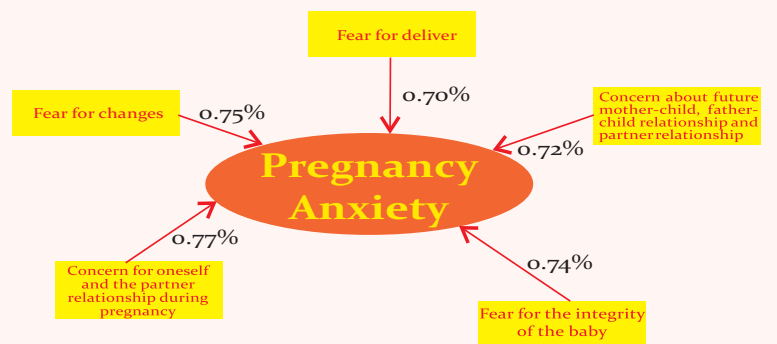

Figure 2. The conf irmatory five-factor model of PRAQ. Based on the result of second-order factor analysis, correlation or loadings of each factor with total scale.

Reliability of the pregnancy related anxiety questionnaire test retest (pearson correlation), Cronbach Alpha and split-half coefficient (split method) were used for evaluating external and internal reliability. The results are shown in Table-4.

Table 2: Distribution of MEQ scores, ESS scores, GHQ-12 scores and DT scores as a function of age in traff ic police off icers.

\begin{tabular}{llll}
\hline Factors & $\begin{array}{l}\text { Cronbach's } \\
\text { alpha }\end{array}$ & $\begin{array}{l}\text { split-half } \\
\text { reliability }\end{array}$ & Re test \\
\hline FC & $0.69^{* *}$ & $0.92^{* *}$ & $0.72^{* *}$ \\
FI & $0.74^{* *}$ & $0.60^{* *}$ & $0.65^{* *}$ \\
FD & $0.76^{* *}$ & $0.57^{* *}$ & $0.69^{* *}$ \\
CFR & $0.72^{* *}$ & $0.64^{* *}$ & $0.72^{* *}$ \\
CPR & $0.70^{* *}$ & $0.59^{* *}$ & $0.68^{* *}$ \\
General & $0.78^{* *}$ & $0.64^{* *}$ & $0.74^{* *}$ \\
\hline
\end{tabular}

${ }^{* *} \mathrm{P}<0.01$

As the above table revealed the results of Cronbach's alpha coeff icient of pregnancy-related anxiety questionnaire has a high internal consistency (Cronbach's alpha $=0.78$ ). Cronbach's alpha for the scales are (selfcentered fear $=0.69$ ), (fear of child with health issues $=0.74)$, $($ fear of childbirth $=0.76),($ fear of change $=0.72)$ and (fear of change in marital relationships $=0.70$ ). Retest reliability within a month for the pregnancy-related anxiety questionnaire is 0.74 and for its dimensions are varied from 0.65

\section{Discussion:}

Uncontrolled stress affects the mother's health as well as the health of the fetus. Early detection of stress in pregnant women and providing the necessary instructions to overcome the same can provide the pregnant women with a pleasant experience. From the very beginning, a tool with high reliability and validity seems necessary to achieve this goal (Cha \& Masho, 2013). The results showed that the psychometric properties of the Persian version of Van den Bergh pregnancy anxiety questionnaire for use in Iranian population and using it in clinical practice and research is acceptable. This finding in total was relevant with the results of the factor analysis of the original developers of the questionnaire (Van den berg, 1990) It could be seen that despite cultural differences in psychological variables in different societies, the concerns about pregnancyrelated issues is worldwide the same. Also, the concurrent validity of the questionnaire showed that this tool has a high correlation with its parallel questionnaire (Beck Anxiety Inventory), and it seems that they measure similar structure.

The analysis focused on the reliability of questionnaire that examined two aspects of test-retest reliability and internal consistency of questionnaire which had led to some good results. In terms of reliability and stability of the test that examined through test-retest coefficient, the results showed that the questionnaire is reliable and its result can be trusted in multiple implementations. Also, high coefficient rates of internal consistency show that questionnaire has a consistent structure; which is consistent with the results of Huizink et al., (2013) and Babanazari \& Kafi (2008) in this regard. Conclusively, on the basis of the findings of this study, it could be suggested that assessment of anxiety and response of pregnant women to the anxiety during pregnancy, along with monitoring and evaluation of health care is beneficial. Special educational and therapeutic approaches to identify stressors and training coping strategies to them can be useful in pregnant women.

Acknowledgements:

We thank all the participants and hospital owners and staff who were helped us directly and/or indirectly to complete this study.

\section{References:}

Arai, Y.C., Ueda, W., Ushida, T., Kandatsu, N., Ito, H., \& Komatsu, T. (2009): Increased heart rate variability correlation between mother and child immediately pre-operation. Acta Anae Scan., 53(5), 607-610.

Babanazari, L., \& Kafi, S.M. (2008): Anxiety to its Different Periods, Sexual Satisfaction and Demographic Factors. Iran. Psyc. Clin. Psychol., 14(2):206-213.

Beck, A.T. \& Steer, R.A. (1990): Manual for the Beck anxiety inventory. San Antonio, TX: Psychological Corporation.

Bhagwanani, S.G., Seagraves, K., Leroy, J., Dierker, M., \& Lax, M. (1997): Relationship between prenatal anxiety \&prenatal outcome in nulliparous woman: a prospective study. J. Natl. Med.Assoc., 89(2):93-8.

Bunevicius, A., \& Cesnaite, E. (2007): Antenatal maternal mental state and anthropometric characteristics of the neonates: impact of symptoms of depression and anxiety. Biol. Psich. Psichofarmakologija, 91:3-6.

Cha, S., \& Masho, S.W. (2013): Preterm Birth and Stressful Life Events. Published by: Intech Open access

Christian, L. M. (2012): Psychoneuroimmunology in pregnancy: Immune pathways linking stress with maternal health,adverse birth outcomes, and fetal development. Neur. E Biob. Revi., 36(1):350-61.

Cookson, H., Granell, R., Joinson, C., Ben, S.Y. \& Henderson, A.J. (2009): Mother's anxiety duringpregnancy isassociated with asthma in their children. J. All. Clin. Imm., 123(4): 847-53. 
Dennis, K.K., Kerim, M.M., David, J.C. \& Andrea, M.M. (2008). Prenatal stress and risk for autism. Neur. Bio. Beh. Rev., 32 (8): 1519-1532.

DiPietro, J.A., Ghera, M.M., Costigan, K. \& Hawkins, M. (2004): Measuring the ups and downs of pregnancy stress. J. Psych. Obst. E Gyn., 25(3-4):189-201.

Dunkel-schetter, C. (1998): Maternal stress and preterm delivery. Pren. Neo. Med., 3:39-42.

Farland, J.M., Salisbury, A.L., Cynthia, L.B., Hawes, K., Halloran, K.K. \& Lester, B.M. (2011): Major depressive disorder during pregnancy and emotional attachment to thefetus. Arch. Women. Men. Heal. 14(5): 425-434.

Goodman, J.H., \& Tyer-Viola, L. (2010): Detection, Treatment, and Referral ofPerinatal Depression and Anxiety by Obstetrical Providers. L. Women Heaalth.,19(3):219-229.

Heidi, S.K., Christine, D.S., Laura, M.G., Calvin, J.H., Curt, A.S. (2014): Pregnancy anxiety and prenatal cortisol trajectories. Biolo. Psyc., 100:13-9.

Huizink, A.C., Mulder, E.J., Robles de Medina, P.G., Visser, G.H., \& Buitelaar, J.K. (2004): Is pregnancy anxiety a distinctive syndrome? Early Hum. Dev.,79(2), 81-91.

Isohanni, M., Jones, P., Kemppainen, L., Croudace, T., Isohanni, I. \& Veijola, J. (200o): Childhood and adolescent predictors ofschizophrenia in the Northern Finland 1966 birth cohorta descriptive life-span model. Eur Arch Psy Clin Neur., 250(6): 311-319.

Kammerer, M., Adams, D., Castelberg, Bv. \& Glover, V. (2002): Pregnant women become insensitive to cold stress. $\underline{B M C P r e}$ Chil., 2(1):8.

Kaviani, H., \& Mousavi, A.S. (2008): Psychometric properties of the Persian version of beck anxiety inventory (BAI). T. Uni. Med.J., 65(2):136-140.

Madhavanprabhakaran, G. K., D'Souza, M. S., \& Nairy, K. S. (2015). Prevalence of pregnancy anxiety and associated factors. Int. J. Afr. Nur. Sci., 3, 1-7.

Martin, J.L., \& Vance, C.S. (1984): Behavioral and psychosocial factors in AIDS: Methodological and substantive issues. $\underline{A M}$ Psychol., 39(11):1303-1308.

Nouri, P.H., Alimohammadi, I., Arghami, Sh., Ghohari, M.R., \& Farshad, A.A. (2010): Assessment of reliability and validity of a new safety culture questionnaire. Iran. Occu. Hea., 7(1):1825 .
O'Connor T.G., Caprariello, P., Blackmore, E.R., Gregory, A.M. \& Fleming, G.P. (2007): ALSPAC Study Team. Prenatal mood disturbance predicts sleep problems ininfancy and toddlerhood. Early Hum. Develop. J., 83 (7):451-458.

O'Connor, T.G., Heron, J., Golding, J., Beveridge, M., \& Glover, V. (2002): Matranal antenatal anxiety and children's behavioral/ emotional problems at 4 years. Report from the Avon longitudinal study of parents and children. $\underline{B r}$. I. Psychiatry, 180:502-508.

O'Keane, V. (200o). Evolving model of depression as an expression of multiple interacting risk factors. Br. J. Psychiatry, 177: 482483.

Punamäki, R.L., Repokari, L., Vilska, S., Poikkeus, P., Tiitinen, A., Sinkkonen, J. \& Tulppala, M. (2006): Maternal mental health and medical predictors of infant developmental and health problems from pregnancy to one year: does former infertility matter? Inf. Beh. Develop.,29(2): 230-242.

Rahman, A. \& Creed, F. (2007): Outcome of prenatal depression and risk factors associated withpersistence in the first postnatal year: prospective study from Rawalpindi, Pakistan. J. Affect. Disord., 100(1):115-21.

Saisto, T., \& Halmesmaki, E. (2003): Fear of childbirth: a neglected dilemma. Acta. Obst. Gyn. Sca., 82(3):201-208.

Schumacker,R.E. \& Lomax, R.G. (2010): A beginner's guide to structural equation modelling, 3rd Ed. Published by Routledge Taylor \& Francis Group.

Solchany, J.E. (2003): Promoting maternal mental health during pregnancy. Theory, practice $\&$ intervention. Washington: NCAST PublicationSeattle.

Van den Bergh, B.R., Mulder, E.J., Mennes, M. \& Glover, V. (2005): Antenatal maternal anxiety and stress and then eurobehavioural development of the fetus and child: links and possible mechanisms. A review. Neur. Biob. Rev., 29(2): 237-258.

Vanden berg, B.R. (1990): The influence of maternal emotional during pregnancy on fetal\& neonatal behavior. Pre. Psyc. J., 5(2):119-130.

WHO. (2013). World Health Organization Report: Maternal mental health and child health and development inlow and middle income countries: report of meeting held in Geneva, Switzerland. 